\title{
Titanium based cranial reconstruction using incremental sheet forming
}

\author{
B. Lu $\cdot$ H. Ou $\cdot$ S. Q. Shi $・$ H. Long $\cdot$ J. Chen
}

Received: 21 August 2014 / Accepted: 1 December 2014 / Published online: 11 December 2014

(C) The Author(s) 2014. This article is published with open access at Springerlink.com

\begin{abstract}
In this paper, we report recent work in cranial plate manufacturing using incremental sheet forming (ISF) process. With a typical cranial shape, the ISF process was used to manufacture the titanium cranial shape by using different ISF tooling solutions with and without backing plates. Detailed evaluation of the ISF process including material deformation and thinning, geometric accuracy and surface finish was conducted by using a combination of experimental testing and Finite Element (FE) simulation. The results show that satisfactory cranial shape can be achieved with sufficient accuracy and surface finish by using a feature based tool path generation method and new ISF tooling design. The results also demonstrate that the ISF based cranial reconstruction has the potential to achieve considerable lead time reduction as compared to conventional methods for cranial plate manufacturing. This outcome indicates that there is a potential for the ISF process to achieve technological advances and economic benefits as well as improvement to quality of life.
\end{abstract}

Keywords Incremental sheet forming · Cranial plate reconstruction · Finite element

B. Lu $\cdot$ J. Chen

Department of Plasticity Technology, Shanghai Jiao Tong University, 1954 Huashan Road, Shanghai 200030, People's Republic of China

H. Ou $(\bowtie) \cdot$ S. Q. Shi

Department of Mechanical, Materials and Manufacturing

Engineering, University of Nottingham, Nottingham NG7 2RD, UK

e-mail: h.ou@nottingham.ac.uk

B. Lu $\cdot \mathrm{H}$. Long

Department of Mechanical Engineering, University of Sheffield,

Sheffield S1 3JD, UK

\section{Introduction}

Cranioplasty is a surgical procedure for the repair of deformity of a human skull due to brain tumour, stroke or traumatic injuries. Cranioplasty surgery does not only offer cosmetic and sometimes lifesaving benefits but also give relief to psychological drawbacks and improve the quality of life of patients [1]. Cranioplasty surgical procedures may be conducted by using autografting (implant taken from patient own body) and allografting (implant taken from a donor body) or alloplastic (non-biologic such as polymeric and metallic) materials. Non-metallic materials such as Polymethylmethacrylate (PMMA), Polyetheretherketone (PEEK) and Hydroxyapatite, and metallic substitutes such as stainless steel and titanium, alloplastic materials are commonly used in cranioplasty surgeries. The selection of cranioplasty materials is normally based on the requirements of such as biocompatibility, material properties and surgeon's experience and preference. Technical readiness for clinical application, short lead time, low cost and ease of manufacture for alloplastic cranioplasty are also important considerations [2].

Among all alloplastic materials including PMMA and PEEK, titanium continues to be the main stream material used in cranioplasty surgeries because of its excellent biocompatibility, resistance to infection, excellent material property, strength and lightweight. However, in spite of the common use and increasing need for titanium based cranial reconstruction, there is a wide variety of methods including casting [3], manual shaping $[4,5]$ and rubber press forming [6-8] commonly used in the manufacture of cranial reconstruction. Even with the assistance of advanced CAD/CAM (computer-aided design and manufacture), computed tomographic (CT) and magnetic resonance imaging (MRI) technologies [2, 3, 6-8], the processes needed to manufacture customised casting moulds, templates and forming dies in conventional methods of cranial manufacturing is not only costly but also time 
consuming often normally requiring a few days up to 2 weeks to completion depending on considerations of such as technical planning and whether there is a case of surgical urgency $[2$, $6,7]$. In recent years, $3 \mathrm{D}$ printing or additive manufacturing based technologies have made rapid advances and it is possible to complete the $3 \mathrm{D}$ printing of a cranial or a maxillofacial prosthetic part within several hours $[9,10]$. However, there are still a number of impediments including insufficient material properties and high cost issues to be overcome before its wide adoption for clinical applications [11].

The ISF process is centred on material plastic deformation of symmetric and asymmetric shapes of sheet metals by tracing a rotational tool along a sequence of contour lines generated directly from part CAD model [12]. Its excellent adaptability to CNC (Computer Numerical Control) systems through direct control of CAD data, with the minimum use of complex tooling, dies and forming press, makes the process cost-effective and easy to automate and adapt for various applications. The localised plastic deformation taking place incrementally ensures improved material formability and this makes it suitable for a wide range of sheet metal materials including titanium. Therefore, it is particularly attractive for manufacturing high value-added, small batch and customised sheet parts. In the past decade, significant progress has been made in the research of ISF technology. In the ISF process development, conventional single point incremental forming (SPIF) [13], two-point incremental forming (TPIF) [14], hybrid forming by combining stretch forming and incremental sheet forming [15] and double side incremental forming (DSIF) [16] have been developed in recent years. Concerning the deformation and fracture mechanisms, different theories including bending under tension(BUT) [17], through-thickness shear effect $[18,19]$ and the "noodle theory" [20] has been proposed. The forming accuracy and the surface finish of the final part have also been investigated [21, 22]. Thanks to these efforts, the application of ISF technology in the real-world becomes possible.

In the application of the ISF technology, the advances of ISF make it specially suitable for manufacture small-batch or customised components, such as those in automobile [23], aerospace [24] and medical application [25]. In a recent paper, effort was made to use ISF to manufacture cranial reconstruction [26]. Whilst the study demonstrated the soundness of ISF based approach for cranial manufacturing, unintended failures in forming high wall angle cranial shape and insufficient accuracy of the formed cranial plate were encountered. From the skull geometry of a patient to a manufactured cranial plate, a few challenges still exist including the formability of material, the geometric construction with ISF toolpath generation, the geometric accuracy and the final surface finish of the cranial plate. Although these topics may have been individually examined in the past of ISF research, these challenges need to be further investigated for the potential practical application in cranial reconstruction.

This paper aims to study the feasibility of manufacturing customized titanium cranial plates by using the ISF approach. In this paper, the material properties of Grade 1 pure (TA1)titanium sheets were firstly investigated. To evaluate the friction effect between the tool and sheet, both conventional ball-head rigid tool and a roller ball tool were employed in the forming process and the surface finish after ISF process was examined. By taking a typical cranial shape, the cranial geometric shape for ISF processing was constructed and the tool path was generated. With the support of FE simulation, a series of ISF experiments were carried out to examine the feasibility of incremental sheet forming for manufacturing cranial plates. By investigating the forming load, material deformation with consideration of thickness distribution and surface finish, a detailed assessment of the ISF based cranial reconstruction is conducted. This is followed by concluding remarks for future work.

\section{Material and methods}

Material properties of (TA1) titanium sheets

TA1 titanium material contains $99.67 \%$ of titanium, $0.08 \%$ of carbon and $0.03 \%$ of iron and $0.22 \%$ of other compositions such as oxygen and hydrogen. Table 1 shows the material properties of TA1 pure titanium.Concerning the ISF processing of TA1 material, from the manufacturing point of view, the flow stress and material ductility are the two key factors that affect the ISF process: the flow stress including the initial yielding and strain hardening which determine the forming load and corresponding contact pressure between tool-sheet interfaces. Although it is proven that ISF enables enhanced formability, the ductility of material is still a key factor that would affect the potential ISF formability, which is important for the successful implementation of incremental forming. In this work, the material properties of TA1 titanium material are examined by using tensile tests on an Instron tensile testing machine, as shown in Fig. 1.

Table 1 Material properties of TA1 pure titanium

\begin{tabular}{lllll}
\hline $\begin{array}{l}\text { Young's } \\
\text { modulus E }(\mathrm{MPa})\end{array}$ & $\begin{array}{l}\text { Yield strength } \\
\sigma_{S}(\mathrm{MPa})\end{array}$ & $\begin{array}{l}\text { Elongation } \\
\delta(\%)\end{array}$ & $\begin{array}{l}\text { Tensile stress } \\
\sigma_{\mathrm{b}}(\mathrm{Mpa})\end{array}$ & $\begin{array}{l}\text { Poisson's } \\
\text { ratio }\end{array}$ \\
\hline 105,000 & 205 & 36 & 370 & 0.37 \\
\hline
\end{tabular}


Fig. 1 Tensile test of

TA1 titanium sheet
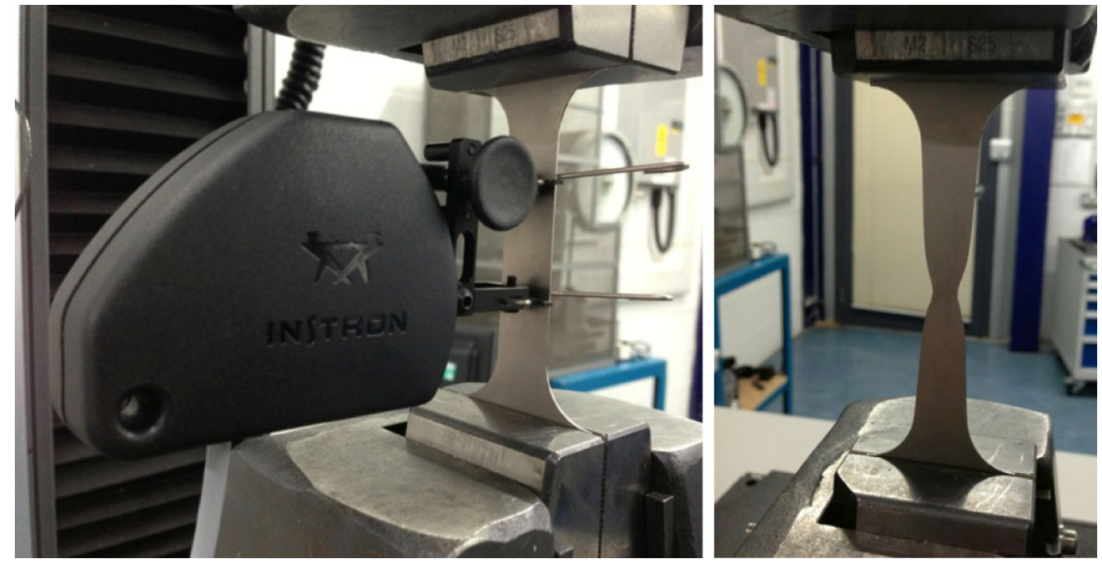

Figure 2 shows the flow stress of TA1 titanium. As can be seen from the figure, the initial yield stress is about $200 \mathrm{MPa}$ while the stress at fracture is about $350 \mathrm{MPa}$ due to strain hardening. Concerning the material ductility, TA1 titanium shows good elongation property in the tensile test. Although the measured elongation is different, the minimum value can be over $35 \%$, which indicates good material formability in incremental sheet forming process. Based on this elongation, the maximum achievable ISF forming angle may be up to $40^{\circ}$ by calculation from Sine law. With the consideration of increased formability in ISF process comparing to tensile test, the maximum achievable forming angle is even higher in a single pass ISF process. The tensile test results suggested a good potential of this material to be used in ISF process.

\section{Evaluation of friction between tool and sheet}

The severe contact condition between the tool and sheet could cause rough surface finish of the cranial plate after ISF process. In order to solve this problem, instead of using the conventional ball head rigid tool, a roller ball tool could be a better option to the conventional tool for the material such as pure titanium that is easy to be

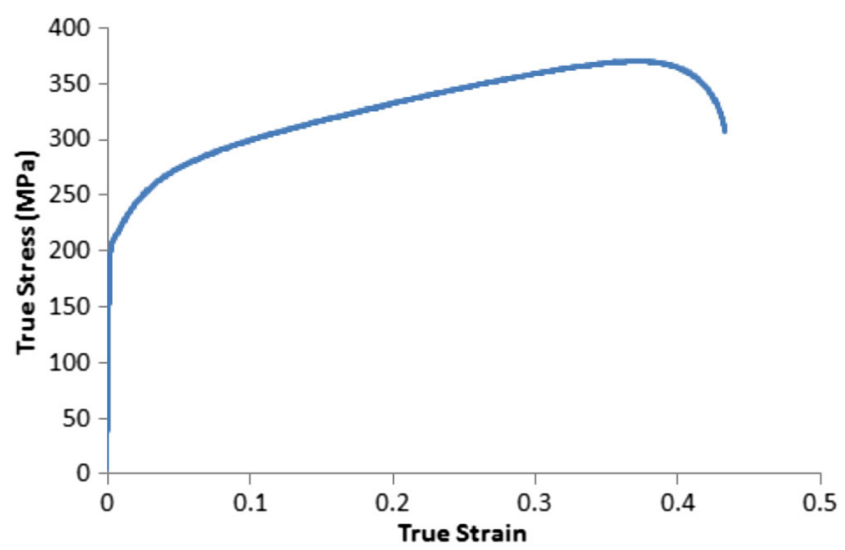

Fig. 2 Flow stress of TA1 titanium scratched. In this way, the conventional sliding friction condition in the ISF process can be replaced by the rolling friction condition, which proves to be effective preventing the potential scratch of the sheet surface in ISF processing [19]. Figures 3 and 4 show the two types of tools used in incremental forming of the cranial plates.

Geometric definition and ISF tool path generation

Generation of the ISF toolpath is a key step for ISF based cranial reconstruction. In the conventional ISF technology, toolpaths may be generated directly through CADbased freeform surface or discrete surface represented by STereoLithography (STL). In practical application for cranioplasty, the geometric data of a skull shape to be reconstructed are typically from the point cloud from CT scan for subsequent model repair [27]. Concerning the technical approach based on the scanned points cloud, the toolpath generation via STL model seems to

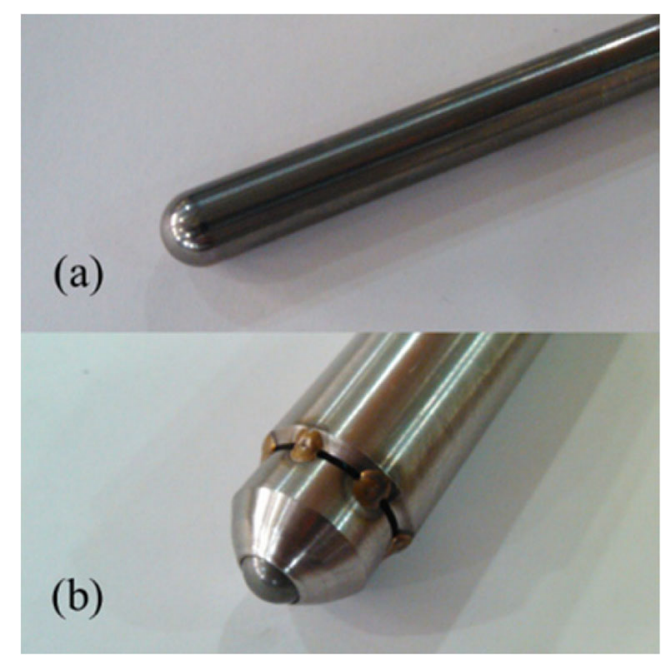

Fig. 3 ISF tools for cranial plate forming: a conventional ball-head rigid tool; b roller-ball tool 
Fig. 4 Geometric construction for cranial plate model. a Skull model b Cranial model taken for ISF construction
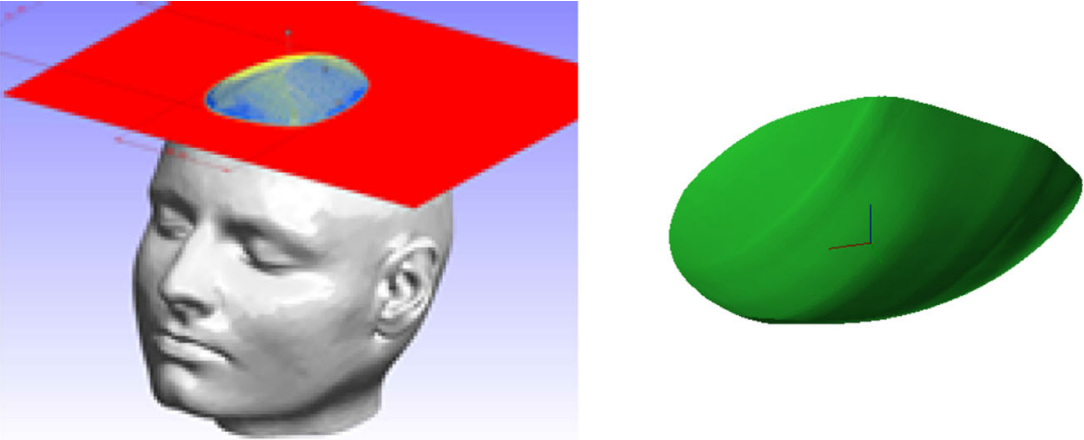

(a) Skull model

(b) Cranial model taken for ISF construction be more convenient than the approach of free form surface generation as the reverse engineering technique can be avoided in reconstructing the CAD surface through point cloud. In this work, a cranial shape from a human skull of point cloud was employed. Although model repair may be required due to traumatic tissue loss in some cases, no model repair is implemented in this work and the surface model is directly taken from the top of the cranium as a demonstration of the ISF based cranial reconstruction technique.

Based on the geometrical shape of the cranial plate, an offset model with consideration of tool radius was established. Spiral tool paths with scallop height of $0.005 \mathrm{~mm}$ are generated based on the z-level slicing approach described in authors' previous work [22]. In the $\mathrm{z}$-level slicing approach, the toolpaths are generated by interpolation to the contour lines of the model in the vertical direction. Figure 5 shows the toolpath generated for ISF processing of the cranial plate. By considering the total length of the toolpath and a feed rate of $2000 \mathrm{~mm} / \mathrm{min}$, the whole ISF process for the cranial plate manufacturing requires $12 \mathrm{~min}$ to complete, which is generally much more efficient than many conventional forming based techniques for cranial reconstruction where additional dies and moulds are necessary.

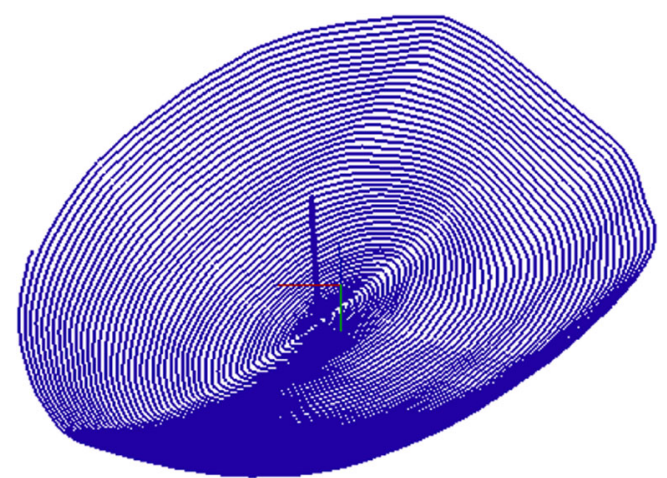

Fig. 5 ISF tool path generated for cranial plate manufacture
FE modelling

As an effective method for analysing material deformation and other concerned issues such as accuracy and material thinning and strain distribution of the workpiece, FE method was used to investigate the sheet deformation in ISF processing for the cranial plate. In this work, ABAQUS Explicit software package was employed. Using the flow stress results obtained from the tensile test and the toolpath generated based on the cranial geometry, an FE model was built as shown in Fig. 6. As shown in the figure, a roller-ball tool with diameter of $10 \mathrm{~mm}$ other than the conventional rigid tool was employed in the ISF simulation. The $10 \mathrm{~mm}$ wide purple region to the edge of the blank was constrained to represent the clamping of the workpiece onto the fixture. The friction coefficient was set to be 0.05 for the contacts between the tool and sheet [28]. A backing plate is placed underneath the sheet to support the part. The mesh size is $1 \mathrm{~mm}$ with approximately 50,000 elements. The original feed rate of the tool was set to be $2000 \mathrm{~mm} / \mathrm{min}$. However, in order to improve the simulation efficiency, the virtual forming speed was scaled up by 100 times according to the best practice

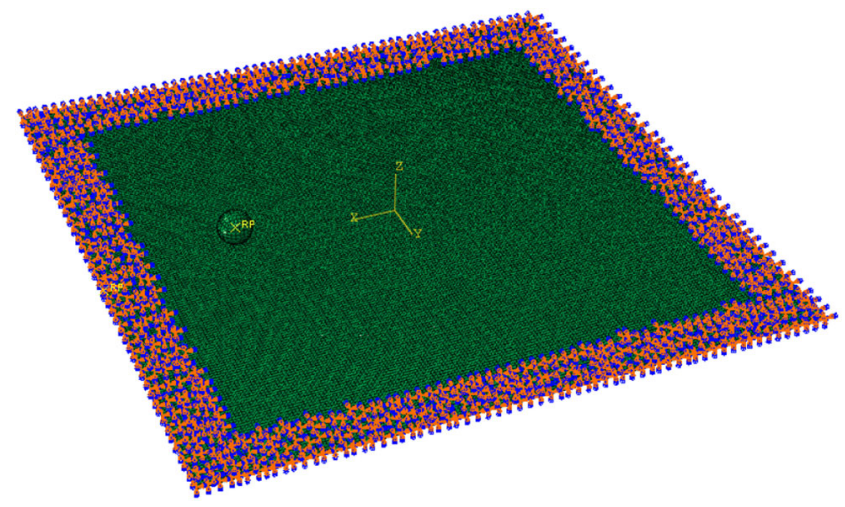

Fig. 6 - FE model for forming of cranial plate 
Fig. 7 ISF experiments of cranial plate forming a ISF experiment $\mathbf{b}$ Finished part

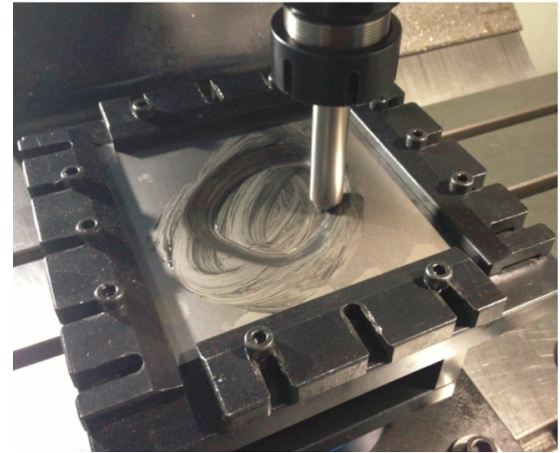

(a) ISF Experiment

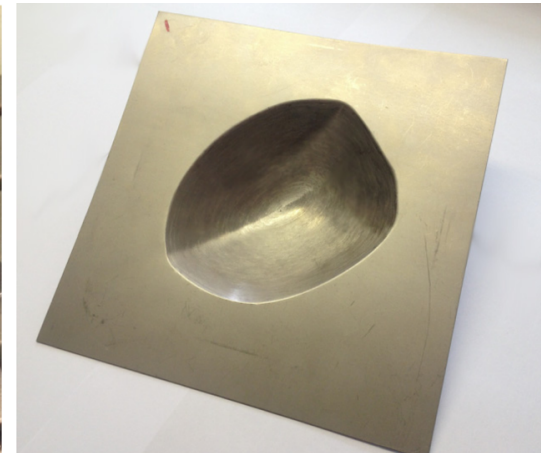

(b) Finished part
[28], in which the ratio of kinematic energy to total energy can be controlled within a limited value. By using this model, the ISF process for cranial plate construction can be analysed and the simulation results compared with experiment.

\section{Experimental setup}

To facilitate the incremental forming for the cranial plate, ISF experiments were conducted by using a 3axis milling machine. Figure 7 shows the setup of the ISF process and one of the formed cranial plates with the roller ball tool. TA1 titanium sheet with a thickness of $0.5 \mathrm{~mm}$ was used for ISF based forming of the cranial plate. Both conventional ball-head rigid tool and the roller ball tool, as shown in Fig. 3 were used for comparison. Rocol RTD compound was employed as the lubricant during the forming process. The tool path generated in Section 2.3 was converted to $\mathrm{NC}$ code and the forming tool moved along this pre-defined path during the ISF process. The feed rate of the tool was set to be $2000 \mathrm{~mm} / \mathrm{min}$ during forming. During the ISF experiment, a multi-axis JR3 load cell was employed to measure the forming forces during the ISF process.

\section{Results and discussion}

Forming forces

The forming forces from both FE simulation and experiment were obtained as shown in Fig. 8. As can be seen from the figure, similar trend of forming load variations can be observed. The forming loads increase rapidly to its maximum value at the initial forming stage and gradually drop down in the forming process. This variation is depended upon the forming shape and the step down value of the forming path. By examining the maximum forming load, in vertical direction, the value reaches $500 \mathrm{~N}$, while in the horizontal direction, the maximum forming load is $300 \mathrm{~N}$. This result suggests that comparing to other methods such as stamping, the
Fig. 8 Comparison of forming load

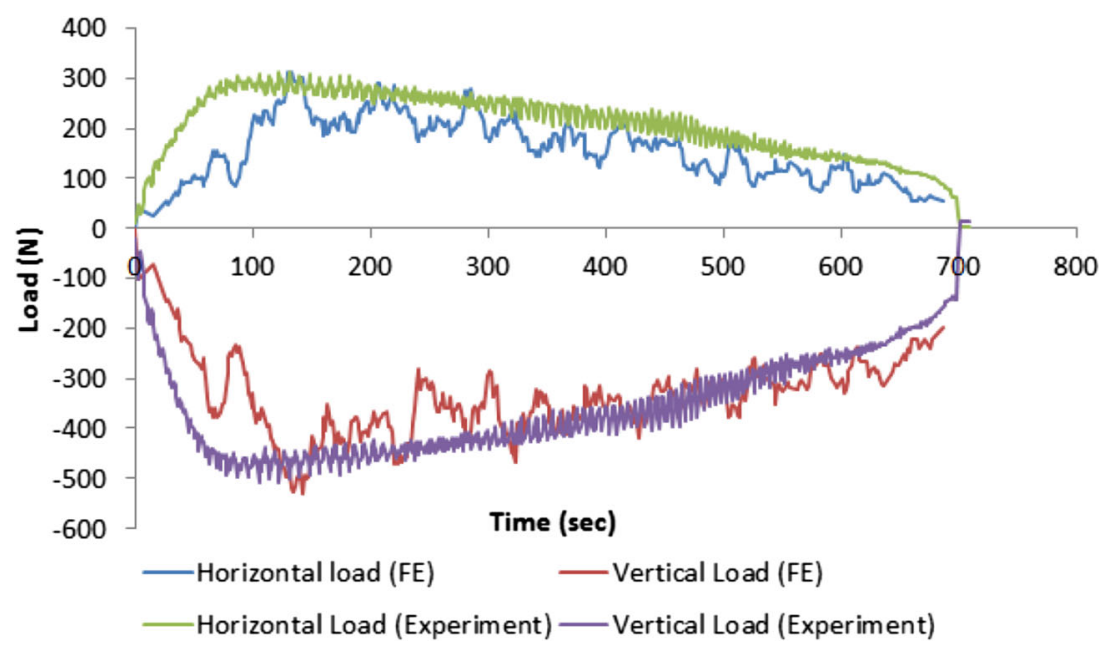


Fig. 9 Distribution of equivalent strain

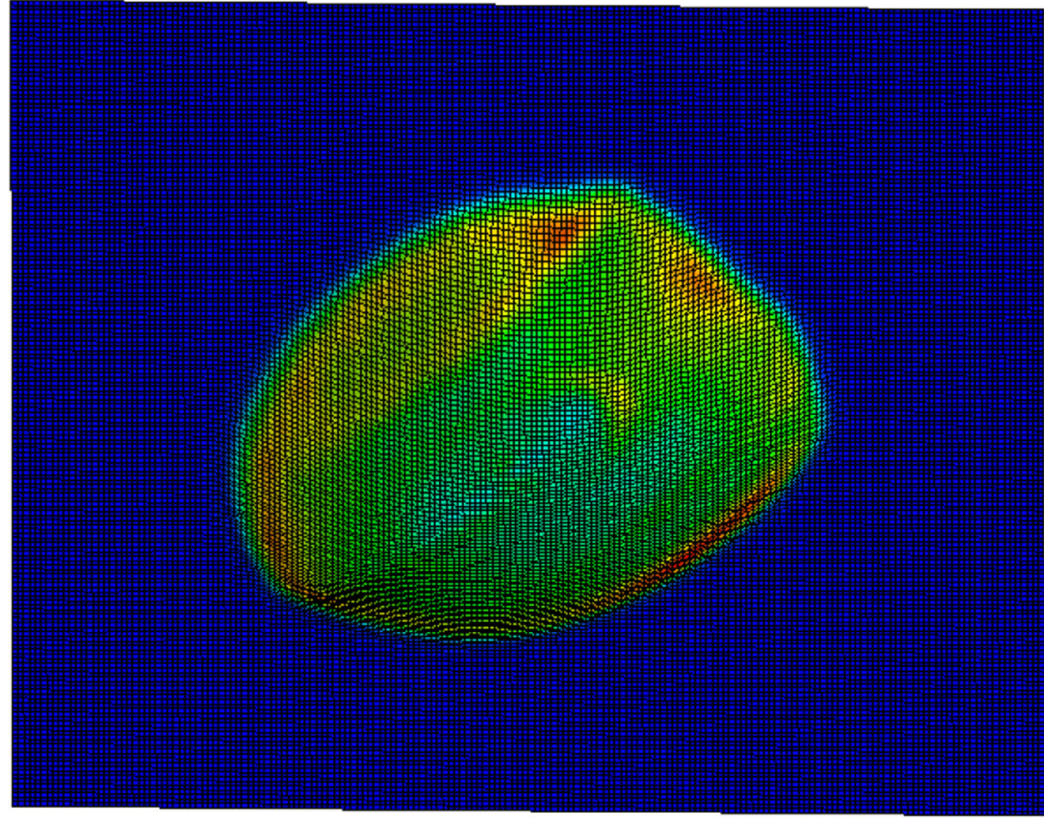

PEEO

SNEG. (fraction $=-1.0$ )

(Avg: $75 \%$ )

$+9.1900-01$ $+8.425 e-01$ $+7.659 e-0$

$+6.893 e-0$
$+6.127 \mathrm{e}-0$
+

$+5.361 \mathrm{e}-0$
$+4.595 \mathrm{e}-0$ $+4.595 e-0$ $+3.063 e-0$ $+2.298 \mathrm{e}-0$ $+1.532 \mathrm{e}-\mathrm{O}$ $+0.0000+00$ forming load is relatively small by using the ISF process for cranial plate manufacturing. In addition, the similarity of forming load from both FE and ISF experimental results suggests that the FE model can be used to provide an accurate prediction of the ISF process for cranial plate manufacturing.

\section{Sheet deformation}

Using the FE model, the strain and thickness distributions of the finished cranial part are obtained. As shown in Figs. 9 and 10, the maximum deformation occurs at the edge of the cranial plate model, where it has the largest wall angle. With the forming process continues, the slope of the wall angle becomes more gradual so the material deformation is less severe.

\section{Sheet thickness}

By examining the thickness distribution obtained from FE simulation, it tends to have the similar variation trend to the material deformation as shown in Fig. 10. With an initial
Fig. 10 Distribution of final sheet thickness

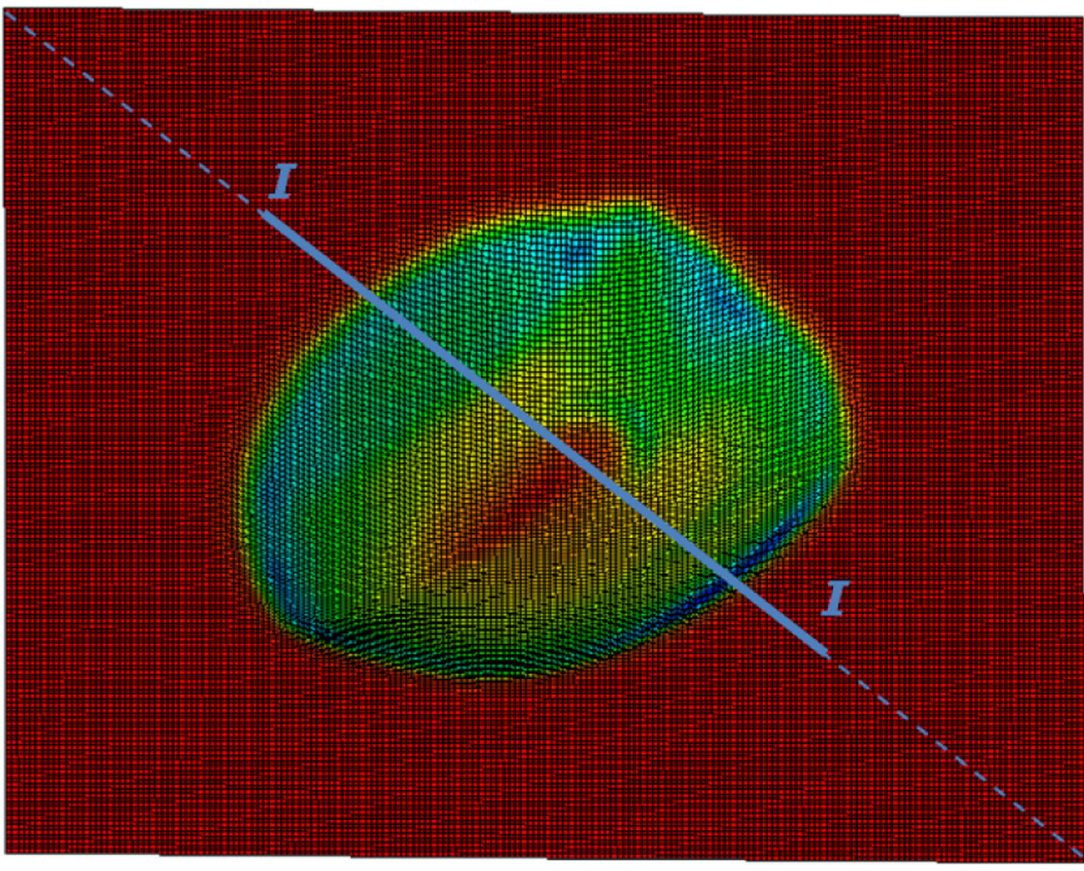

STH (Avg: 75\%) $+5.0000-01$ $+4.9950-01$ $+4.7890-0$ $+45890-01$ $+4.53$ +4367 e+4.367 e$+4.262 \mathrm{e}-0$ $+4.051 \mathrm{e}-0$ +3.945 e- 0 $+3.9400-0$ $+3.734 \mathrm{e}-0$ 
Fig. 11 Thickness distribution along section $I-I$

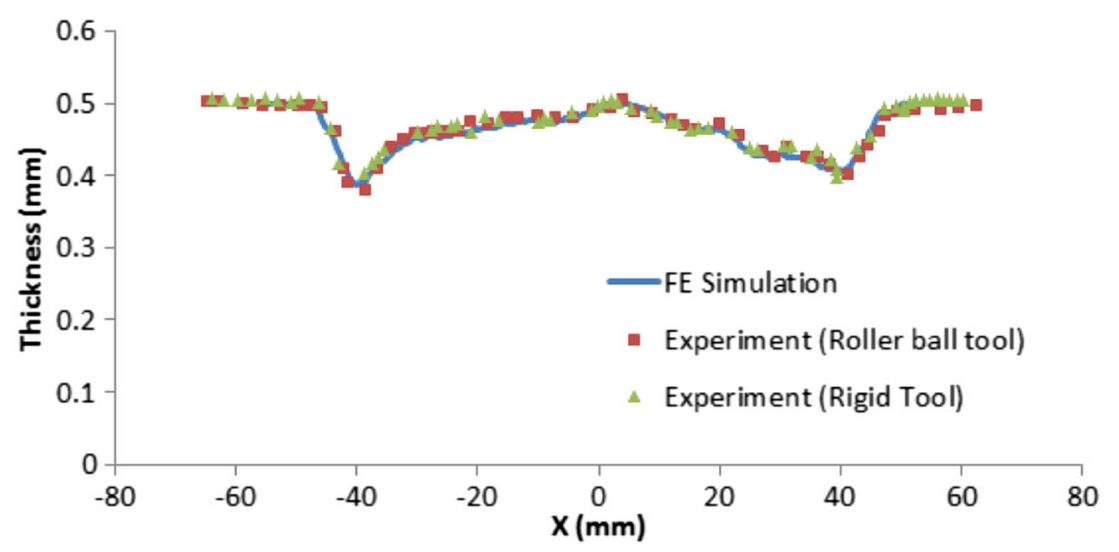

thickness of $0.5 \mathrm{~mm}$, the minimum wall thickness is about $0.37 \mathrm{~mm}$ resulting in a $26 \%$ reduction. The maximum thickness reduction occurs at the edge of the cranial plate whilst in the bottom region, the sheet becomes less deformed. To validate the calculated thickness distribution, the formed cranial parts processed by both the roller-ball and rigid tools were measured by a Mitutoyo CMM Euro-C-A121210 coordinate measurement machine (CMM) and the thickness along section $I-I$ was obtained and compared with the FE results as shown in Fig. 11. As can be seen from the figure, both the rigid and roller-ball tool types produce almost identical thickness distributions. In addition, similar results between FE and experimental results can also be observed. The minimum measured thickness is $0.368 \mathrm{~mm}$, which is very close to the FE thickness result of $0.373 \mathrm{~mm}$. This comparison also suggests the accuracy of FE prediction.

Geometric accuracy

Both the finished parts before and after trimming of the blank from experimental approach were measured by using a
Dantec Q-400 digital image correlation (DIC) system, as shown in Fig. 12, and the scanned point clouds were then reconstructed to STL model so the geometric accuracy of the ISF formed cranial plates can be evaluated by comparing to the nominal shape. Figure 13 shows the geometrical deviation from the nominal shape of parts from both FE and experimental testing. By comparing Fig. 13a and b, it can be found some notable geometric difference between FE and experimental results. The maximum difference is in the region of the bottom of the part reaching $0.5 \mathrm{~mm}$. This discrepancy may be due to the inaccurate prediction of material springback in FE explicit simulation. Concerning the deviation of the actual cranial plate geometry from the nominal shape, it can be found that the maximum deviation is from the edge of the part with a magnitude of $0.5 \mathrm{~mm}$. By measuring the deviation of the trimmed part as shown in Fig. 13c, obvious springback can be observed after removing the blank. The maximum deviation occurs along the trimmed edge with the value of about $3 \mathrm{~mm}$. This springback may be due to the reduced stiffness around the edge after trimming and re-distribution of residual stress. This result suggested

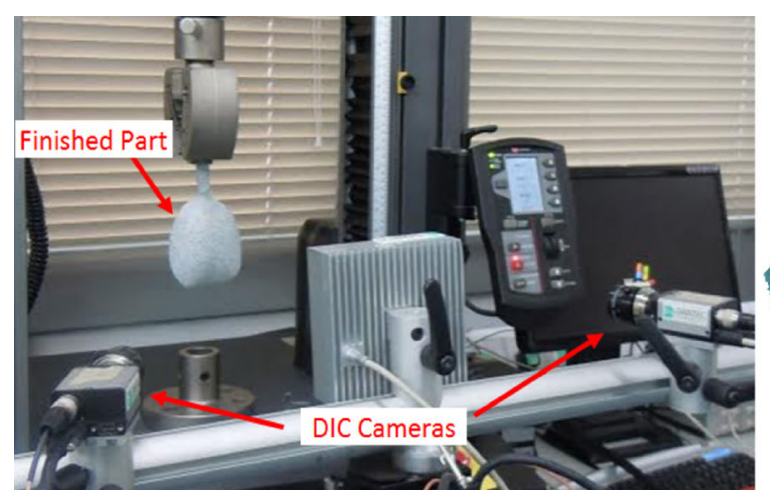

(a) Shape Measurement using DIC system shape

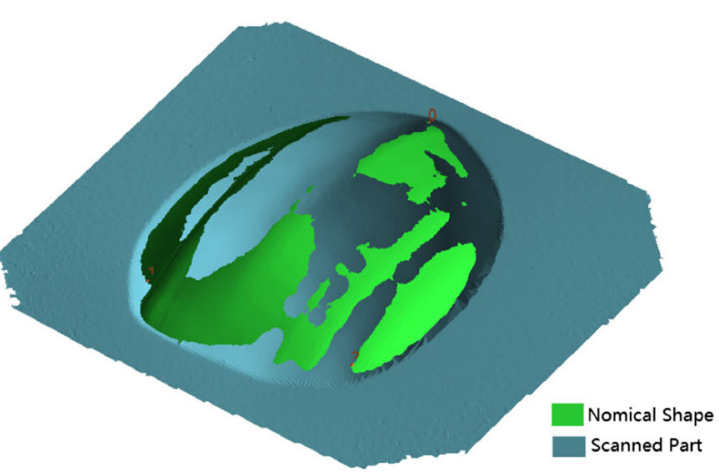

(b) Comparison of the formed part with nominal

Fig. 12 Measurement and evaluation of finished cranial plate. a Shape measurement using DIC system b Comparison of the formed part with nominal shape 
Fig. 13 Geometrical deviation of finished part. a FE simulation $\mathbf{b}$

Untrimmed cranial plate $\mathbf{c}$

Trimmed cranial plate

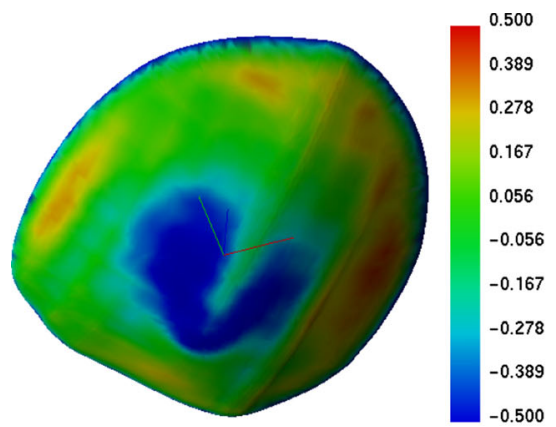

(a) FE simulation

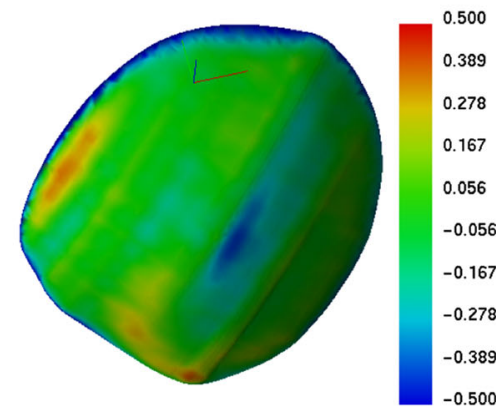

(b) Untrimmed cranial plate

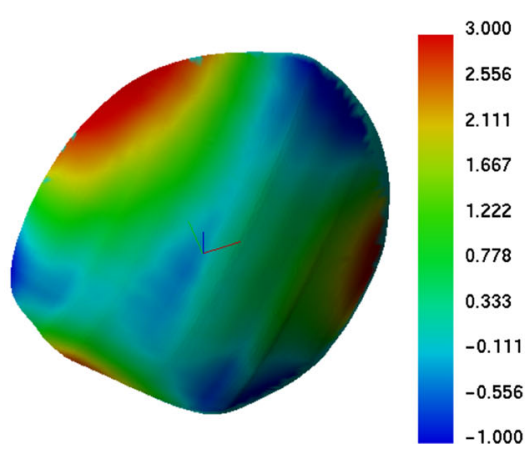

(c) Trimmed cranial plate

that geometric inaccuracy of the cranial plate after the ISF processing and trimming needs to be compensated for to a smaller amount. Further optimisation on ISF toolpath strategies and ISF specific compensation methods may be used to minimise the springback due to such as residual stress redistribution. Alternatively it is possible to manually correct the shape deviation to an acceptable level for cranial reconstruction before more robust optimisation and compensation approaches may be developed $[4,5]$.

\section{Surface finish}

The surface finish of the ISF processed cranial plates can be examined as shown in Fig. 14. Obvious galling can be observed on the part surface processed by the rigid tool. This is due to the adherence of the titanium sheet onto the tool surface and these adhesions further scratch the part surface. Concerning the part processed by the roller ball tool, although tool marks may still be visible, the surface finish is much improved and no adhesion on the part surface can be observed. The detailed surface profiles were examined by using a surface roughness measurement machine as shown in Fig. 15. Obvious difference of profiles can be observed. The $R_{z}$ value of the part processed by the rigid tool is $25.7 \mu \mathrm{m}$ as compared to that of $5.7 \mu \mathrm{m}$ processed by the roller ball tool. As given in same the figure, similar proportion of difference of the $\mathrm{R}_{\mathrm{a}}$ value is obtained. This result further proves that substantial surface roughness improvement may be made by using the roller-ball tool.
Fig. 14 Surface examination of roller-ball tool and rigid tool a Rigid tool b Roller ball tool

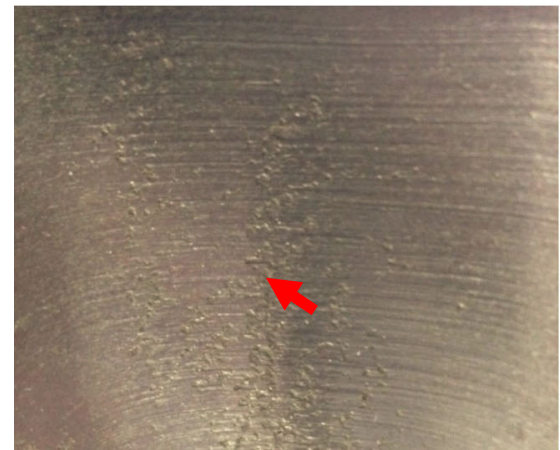

(a) Rigid tool

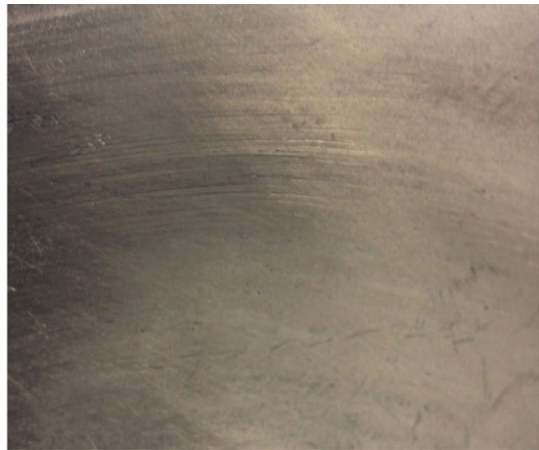

(b) Roller ball tool 


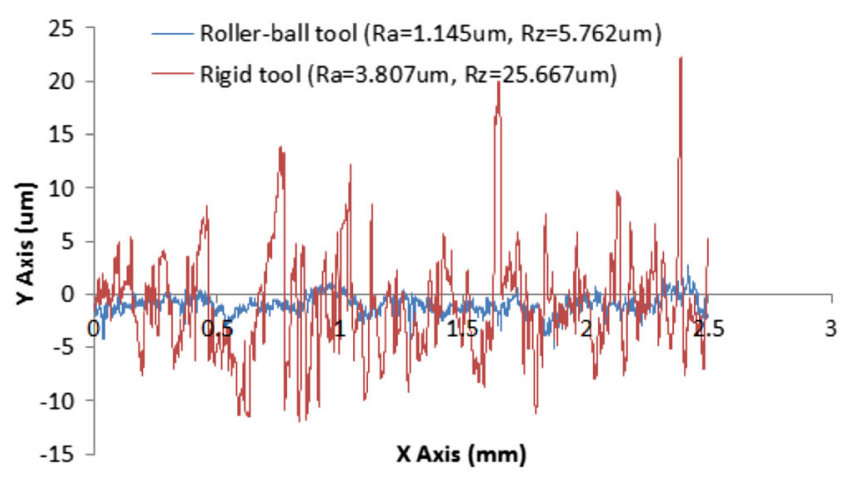

Fig. 15 Comparison of surface profiles of parts processed by roller-ball tool and rigid tool

General assessment of ISF based methods for reconstruction of cranial plates

By evaluating the feasibility and challenges for ISF based cranial reconstruction, this study confirms that the titanium sheet can be produced for cranioplasty applications by using the ISF approach. Comparing to the conventional approaches such as stamping, ISF does not require the preparation of shape specified forming tools, which not only reduces the cost but also the forming time. The localized deformation of the workpiece ensures the enhanced deformation stability and sheet formability as compared to conventional forming methods. By employing the roller ball tool, the surface finish of the formed part can be significantly improved to meet the requirement for surgical operations. Concerning the geometric accuracy, a maximum $3 \mathrm{~mm}$ springback of the trimmed part can be observed at the edge of cranial plate after removal of the blank. As the cranial plate is a thin-wall part with thickness of about $0.5 \mathrm{~mm}$ or less, the stiffness may not be large enough to maintain its original shape during the re-distribution of residual stress in the blank trimming. For clinical implementation of the ISF process in cranial plate manufacturing, three specific aspects need to be considered:

1) Processing technology: In ISF processing of the cranial plate a pre-prepared backing plate was employed in the forming process. A customized backing plate needs to be made to ensure the ISF geometric accuracy. Thus this is still not an entirely "flexible" process. In the future development, a more advanced DSIF (double side incremental forming) technology with a forming tool and a counter tool may be employed to replace the current technology framework of forming tool i.e. the use of a backing plate. Such a solution would further increase the process flexibility and automation.

2) Lubrication: It was found that pure titanium is easy to adhere to the forming tool so roller-ball type tools with lubricants were employed in the experiments. Although surface cleaning process is employed in clinical application, development of new roller ball tool with self-lubricant coating or non-metallic tools to avoid ISF tool and workpiece adhesion would be beneficial for less demand in cranial plate sterilisation.

3) Geometric accuracy: The springback during the trimming of the blank is considerably large. This kind of springback may not be easily avoided as the cranial plate is a thin sheet and the tensile strength of titanium is relatively high. Therefore, for full clinical application of ISF based cranial reconstruction, it is important to develop more robust toolpath strategies to achieve uniform residual stress distribution and to establish more rigorous optimisation and compensation methods for accurate quantification and efficient minimisation of part springback with a given size and shape of cranial plate.

\section{Conclusions}

In this work, by evaluating the material properties of Grade 1 pure titanium sheets, FE simulation and ISF experimental testing for cranial plates, the feasibility of manufacturing customized titanium cranial plates by using the ISF approach is studied and the particular issues and possible solutions were discussed. The conclusions of this work may be summarized as follows:

1) ISF based construction of cranial plate by using Grade 1 pure titanium sheets is a feasible solution and it shows clearly the potential for real medical application.

2) The surface finish and thickness distribution are satisfactory for the application of cranioplasty.

3) Further development is still needed to overcome few specific issues including the current use of backing plate and lubricant, the requirement for new tools as well as the minimisation of springback.

Acknowledgment The authors are grateful for the support provided by the Engineering and Physical Science Research Council of UK (EP/ L02084X/1) and the Marie Curie International Incoming Fellowship $(628,055$ \& 913,055) and International Research Staff Exchange Scheme (IRSES, MatProFuture project, 318,968) within the 7th EC Framework Programme (FP7). The authors wish to thank Dr Mingjun Liu of Cranioplasty Unit, The University College London Hospitals NHS Foundation Trust for reviewing the manuscript and for providing valuable suggestions in cranioplasty, Mr Tom Edgar of Queen's University Belfast for providing the geometric model of the skull for cranial reconstruction; Mr Tom Buss, Jason Young and Mark Daine of University of Nottingham for their support in material testing and cranial plate measurements.

Open Access This article is distributed under the terms of the Creative Commons Attribution License which permits any use, distribution, and reproduction in any medium, provided the original author(s) and the source are credited. 


\section{References}

1. Aydin S et al (2011) Cranioplasty: Review of materials and techniques. J Neurosci Rural Pract 2(2):162-167

2. Spetzger U, Vougioukas V, Schipper J (2010) Materials and techniques for osseous skull reconstruction. Minim Invasive Ther Allied Technol 19:110-121

3. Heissler E et al (1998) Custom-made cast titanium implants produced with $\mathrm{CAD} / \mathrm{CAM}$ for the reconstruction of cranium defects. Int J Oral Maxillofac Surg 27(5):334-338

4. Bartlett P, Carter LM, Russell JL (2009) The Leeds method for titanium cranioplasty construction. Br J Oral Maxillofac Surg 47(3):238-240

5. Bhargava D et al (2010) Construction of titanium cranioplasty plate using craniectomy bone flap as template. Acta Neurochir 152(1): 173-176

6. Joffe J et al (1999) A prospective study of computer-aided design and manufacture of titanium plate for cranioplasty and its clinical outcome. Br J Neurosurg 13(6):576-580

7. Day RE et al (2012) The Royal Perth Hospital method for the design and manufacture of titanium cranioplasty plates. Br J Oral Maxillofac Surg 50:376-377

8. Lieger $\mathrm{O}$ et al (2010) Computer-assisted design and manufacture of implants in the late reconstruction of extensive orbital fractures. Arch Facial Plast Surg 12(3):186-191

9. Rotaru H, et al. Cranioplasty With Custom-Made Implants: Analyzing the Cases of 10 Patients. Journal of Oral and Maxillofacial Surgery. 70(2): p. e169-e176

10. Klein GT, Lu Y, Wang MY (2013) 3D Printing and NeurosurgeryReady for Prime Time? World Neurosurg 80(3):233-235

11. Elahinia $\mathrm{MH}$ et al (2012) Manufacturing and processing of NiTi implants: A review. Prog Mater Sci 57(5):911-946

12. Jeswiet J (2005) Asymmetric Incremental Sheet Forming. Adv Mater Res 6-8:35-58

13. Iseki H, Kato K, and Sakamoto S (1389) Flexible and incremental sheet metal forming using a spherical roller. In: Proc. 40th JJCTP: p. 41-44 (in Japanese).

14. Matsubara S (1994) Incremental Backward Bulge Forming of a Sheet Metal with a Hemispherical Head Tool. J JSTP 35(406):1311-1316
15. Araghi BT et al (2009) Investigation into a new hybrid forming process: Incremental sheet forming combined with stretch forming. CIRP Ann Manuf Technol 58(1):225-228

16. Malhotra R et al (2010) Improvement of Geometric Accuracy in IncrementalForming by Using a Squeezing Toolpath Strategy with Two Forming Tools. J Manuf Sci Eng 133(6):603-611

17. Emmens WC, Boogaard AH (2008) Tensile tests with bending: a mechanism for incremental forming. Int J Mater Form 1(1):1155-1158

18. Allwood JM, Shouler DR (2009) Generalised forming limit diagrams showing increased forming limits with non-planar stress states. Int $\mathrm{J}$ Plast 25(7):1207-1230

19. Lu B et al (2014) Mechanism investigation of friction-related effects in single point incremental forming using a developed oblique rollerball tool. Int J Mach Tools Manuf 85:14-29

20. Malhotra R et al (2012) Mechanics of fracture in single point incremental forming. J Mater Process Technol 212(7):1573-1590

21. Micari F, Ambrogio G, Filice L (2007) Shape and dimensional accuracy in Single Point Incremental Forming: State of the art and future trends. J Mater Process Technol 191(1-3):390-395

22. Lu B et al (2013) Feature-based tool path generation approach for incremental sheet forming process. J Mater Process Technol 213(7): $1221-1233$

23. Lievers WB, Pilkey AK, Lloyd DJ (2004) Using incremental forming to calibrate a void nucleation model for automotive aluminum sheet alloys. Acta Mater 52(10):3001-3007

24. Hussain G et al (2012) Guidelines for Tool-Size Selection for SinglePoint Incremental Forming of an Aerospace Alloy. Mater Manuf Process 28(3):324-329

25. Ambrogio G et al (2005) Application of Incremental Forming process for high customised medical product manufacturing. J Mater Process Technol 162-163:156-162

26. Duflou JR et al (2013) Manufacture of Accurate Titanium CranioFacial Implants with High Forming Angle Using Single Point Incremental Forming. Key Eng Mater 549:223-230

27. Scholz M et al (2007) Reconstruction of the temporal contour for traumatic tissue loss using a CAD/CAM-prefabricated titanium implant-case report. J Cranio-Maxillofac Surg 35(8):388-392

28. Fang $\mathrm{Y}$ et al (2014) Analytical and experimental investigations on deformation mechanism and fracture behavior in single point incremental forming. J Mater Process Technol 214(8):1503-1515 